\title{
Pyloric Pseudodiverticulum: A rare incidental finding during the repair of perforated duodenal ulcer
}

\author{
Kausik Ray
}

Received: 13 January 2009 / Accepted: 14 May 2009

(C) Association of Surgeons of India 2010

An 86-year-old old woman presented with epigastric pain and shock following an esophago-gastro-duodenoscopy for sudden onset of hematemsis and melaena. She had a history of taking diclofenac tablets for arthritis. She also had other co-morbidities like chronic obstructive pulmonary disease, hypertension and atrial fibrillation. The endoscopy finding suggested a bleeding ulcer in the first part of duodenum. Proximal to the ulcer, there was an area of scar tissue of a diameter of about $3 \mathrm{~cm}$, which was suggestive of a healed pyloric ulcer (Fig. 1).

Immediately after the endoscopy, the patient felt unwell and diagnosed clinically and radiologically as perforation of duodenal ulcer. Peroperatively, an antero-medial perforated duodenal ulcer was discovered in the first part of duodenum. A pseudodiverticulum, possibly arising from a healed ulcer, was found proximal to it (Fig. 2). It arose from the pylorus and was firm in consistency, presumably, due to old stomach contents and fibrosis inside. A repair of perforation with omental patch and thorough peritoneal lavage was performed and patient was shifted to intensive therapy unit. Later on, she expired there.

Pyloric diverticulum is one of the most rare findings [1]. Pseudodiverticulum in lower stomach is rare too. Very few related publications are available in medical literature. This case is unique in its appearance and presentation.

\section{K. Ray}

General Surgery Unit, Worthing Hospital,

Worthing, West Sussex,

BN11 2DH, UK

E-mail: ray_kausik2003@yahoo.co.in

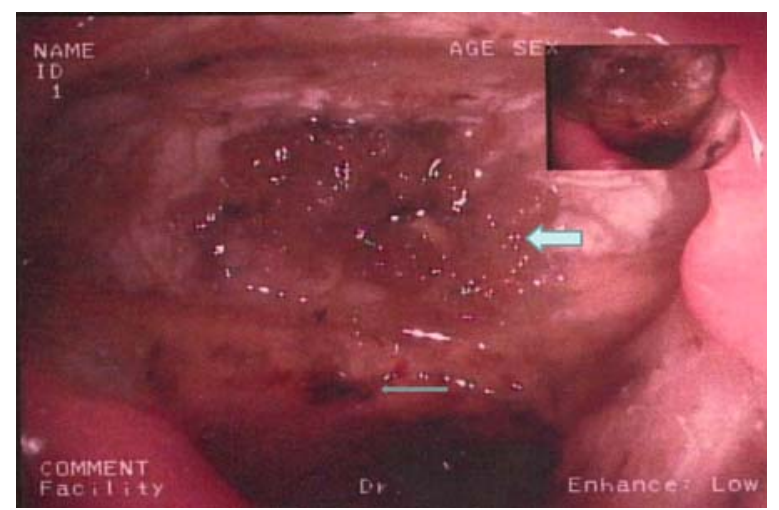

Fig. 1 Area of pseudodiverticular origin from the scar of healed antral ulcer which was partly filled up with old gastric contents (thick arrow). The bleeding duodenal ulcer was visible below (thin arrow)



Fig. 2 Pyloric Pseudodiverticulum from the weak scar of previous ulcer. Perforated duodenal ulcer was just below it (arrow mark)

\section{Reference}

1. Bhattacharya K. (2005) Gastric diverticulum - 'Double pylorus appearance': Images in endoscopy 1 (1):39. 